\title{
DESEMPENHO DE CULTIVARES DE FEIJÃO EM SEMEADURA TARDIA NO PLANALTO CATARINENSE
}

\author{
PERFORMANCE OF BEAN CULTIVARS ON LATER SOWING \\ IN THE SANTA CATARINA PLATEAU
}

\author{
Dilson Antônio Bisognin ${ }^{1}$ Milton Luiz de Almeida ${ }^{2}$ Altamir Frederico Guidolin2 \\ João Antônio do Nascimento ${ }^{2}$
}

\section{RESUMO}

A semeadura tardia é uma prática cultural que vem sendo utilizada pelos produtores de feijão do planalto catarinense, apesar de não recomendada pela pesquisa. Com o objetivo de avaliar o desempenho de cultivares de feijão em semeadura fora da época recomendada, conduziu-se um experimento em Lages, SC, nos anos agrícolas de 1993/94 e 1994/95. Foram utilizadas oito cultivares de feijão, sendo seis do grupo comercial preto e duas do carioca, semeadas em meados de novembro (época recomendada), de dezembro e de janeiro. Os tratamentos foram distribuídos segundo um fatorial $2 \times 3 \times 8$ (ano $x$ época de semeadura $x$ cultivar) em blocos ao acaso, com quatro repetições. $O$ atraso da semeadura reduziu o sub-período emergência-início de florescimento, afetando significativamente o crescimento das plantas. O número de legumes/planta e de grãos/legume e peso de 1000 grãos foram significativamente afetados pelo atraso da semeadura, o que resultou em reduções no rendimento de grãos da ordem de $24,6 \%$ para a semeadura de dezembro e de $56,7 \%$ para a de janeiro, em relação a de novembro, ou seja, uma redução de 0,95\% no rendimento de grãos a cada dia de atraso da semeadura. Concluiuse que o atraso da semeadura de feijão no planalto catarinense reduz significativamente o rendimento de grãos; a indicação desta prática deve ser acompanhada da recomendação de cultivares específicas e de um manejo adequado; $e$ utilizando as recomendações de manejo da cultura do feijão, a cultivar BR/ IPAGRO 1-Macanudo é a de melhor desempenho em semeadura tardia no planalto catarinense.
Palavras-chave: época de semeadura, rendimento de grãos,Phaseolus vulga.

\section{SUMMARY}

Late sowing of beans is not recommended; however, this procedure can prove to be useful to increase productivity to farmer beans of the Santa Catarina plateau. An experiment was carried out in Lages, SC, in 1993/94 and $1994 / 95$ growing season with the objective to evaluate the performance of bean cultivars sowed late in the season. Eight cultivars, six of which belong to black beans group and two to "carioca" bean cultivars were sowing in November (recommended period) December and January. The experimental design was a factorial $2 \times 3 \times 8$ (year $x$ season of sowing $x$ cultivar) in a completely randomized block, design with four repetitions. The crop growing and period of emergency-blossom was affected by later sowing. Yield components: number of pods per plant and seeds per pod, 1000 seed weight, and grain yield were significantly affected by later sowing. The grain yield was reduced by $24.6 \%$ and $56.7 \%$ in whem sowed December and January to November sowing. Therefore, the grain yield was reduced in $0.95 \%$ to each day of late sowing. The results support the idea that the grain yield of bean cultivars are affected by the later sowing in the Santa Catarina plateau. The practice of late sowing has to be established by recommendation to each cultivars and crop management.

'Engenheiro Agrônomo, Mestre, Professor do Departamento de Fitotecnia, Universidade Federal de Santa Maria, Campus Universitário, 97119-900 - Santa Maria, RS. Autor para correspondência.

${ }^{2}$ Engenheiro Agrônomo, Mestre, Professor do Centro de Ciências Agroveterinárias, Universidade do Estado de Santa Catarina.

${ }^{3}$ Engenheiro Agrônomo, Mestre, Pesquisador da EPAGRI. 
Key words: sowing date, grain yield, Phaseolus vulgaris

\section{INTRODUÇÃO}

A cultura do feijão - Phaseolus vulgaris L. é uma das mais importantes para o Estado de Santa Catarina em área plantada, só perdendo para o milho (INSTITUTO CEPA, 1996). A venda do feijão proporciona a primeira receita das culturas de verão, o que significa uma injeção de recursos em um momento financeiro muito crítico para os pequenos agricultores.

Em Santa Catarina, o feijão tem sido semeado em duas épocas, chamadas de cultivo de safra e de safrinha. O cultivo de safra normalmente compreende os meses de setembro a novembro e o cultivo de safrinha, os meses de janeiro e fevereiro. Segundo o zoneamento agroclimático da cultura para o Estado, no planalto catarinense não se recomenda o cultivo de safrinha, devido a possibilidade de ocorrência de baixas temperaturas no final do ciclo da cultura, as quais podem limitar o rendimento de grãos. Nesta região, a época recomendada de semeadura para o ano agrícola de $1993 / 94$ era entre 20 de setembro a 30 de novembro, sendo que a época preferencial era de 20 de setembro a 30 de outubro (HEMP et al., 1993), o que mantinha uma lacuna nos meses de dezembro e de janeiro, considerados inadequados ao cultivo do feijão no Estado devido a altas temperaturas. No entanto, verifica-se que a temperatura média do ar nos meses mais quentes do ano no planalto catarinense oscila entre 19 e $22^{\circ} \mathrm{C}$, valores que são considerados por ORTEGA et al. (1974) como ideais para o cultivo do feijão.

Muitos produtores do planalto catarinense têm utilizado a semeadura tardia como prática, porém não recomendada pela pesquisa, o que tem trazido problemas com o financiamento bancário. Este procedimento tem sido adotado principalmente nas áreas ocupadas pela cultura do trigo, a qual é normalmente colhida de meados a final novembro. $\mathrm{Na}$ fixação da época de semeadura, diversos fatores do meio são definidos, entre eles a temperatura do ar. Sobre esse aspecto, SINCLAIR (1994) salienta que deve-se considerar quais são os limites que a temperatura estabelece sobre o rendimento potencial da cultura, avaliando a duração da limitação e sua influência sobre as diferentes etapas do crescimento e desenvolvimento da cultura. Este tipo de procedimento é utilizado no Estado de Minas Gerais, onde há quatro épocas de semeadura, as quais apresentam limitações e vantagens distintas (VIEIRA \& FARIA VIEIRA, 1995). Atualmente, os programas de melhoramento genético deste Estado já estão concentrando esforços no lançamento de cultivares específicas para cada região, através da identificação das cultivares mais adaptadas e mais estáveis para cada região e época de cultivo (MIRANDA et al., 1993).

Em trabalho realizado no planalto catarinense com o objetivo de melhorar o aproveitamento da estação estival de crescimento, ALMEIDA \& SANGOI (1994) obtiveram rendimento de grãos entre 1.750 e $2.000 \mathrm{~kg} / \mathrm{ha}$, em semeadura realizada no mês de dezembro na região de Lages/ SC. Tendo em vista estes resultados e a restrita disponibilidade de pesquisas que dêem suporte a recomendação da prática de semeadura tardia de feijão no planalto catarinense, realizou-se este experimento com o objetivo de avaliar o desempenho das cultivares em semeadura fora da época recomendada.

\section{MATERIAIS E MÉTODOS}

O experimento foi conduzido na Estação Experimental da EPAGRI - Lages, SC, nos anos agrícolas de 1993/94 e 1994/95. A análise do solo acusou os seguintes resultados: pH água 6,1 e 6,0; M.O. 3,5 e 4,0\%; K 84 e 80 ppm; e P O 20,7 e 21,2ppm, respectivamente para os dois ano ${ }^{5}$ de condução do experimento. O preparo do solo foi realizado segundo as recomendações técnicas descritas por WILDNER (1992), a adubação segundo BALDISSERA \& SCHERER (1992), o controle de plantas daninhas foi efetuado mecanicamente e de pragas conforme MILANEZ (1992).

Oito cultivares recomendadas de feijão (seis do grupo comercial preto, BR/IPAGRO 1-Macanudo, BR 1-Barriga Verde, FT 120, EMPASC 201, Rio Tibagi e a FT-Tarumã, e duas do grupo comercial carioca, Carioca e Carioca $80 \mathrm{SH}$, também denominada IAC Carioca), foram avaliadas segundo o delineamento blocos ao acaso com quatro repetições, em três épocas (semeadura no dia $15 \pm 3$ dos meses de novembro época recomendada, de dezembro e de janeiro) em dois anos. A unidade experimental foi composta por quatro linhas de 5,0m de comprimento, espaçadas de $0,5 \mathrm{~m}$, sendo a área útil as duas fileiras centrais, eliminandose $0,50 \mathrm{~m}$ de cada extremidade. Quando as plantas apresentavam a primeira folha definitiva, foi efetuado um desbaste deixando-se 10 plantas/m linear, ou 200.000 plantas/ha. Os locais das três épocas, nos dois anos, eram vizinhos e em área manejada de forma similar nos anos anteriores. 
As características avaliadas foram: altura de planta, número de legumes/ planta e de grãos/legume, peso de 1000 grãos e rendimento de grãos a $13 \%$ de umidade. As características de planta e de legume foram avaliadas a partir de uma amostra aleatória de 10 plantas retirada da área útil da parcela, sendo que a altura de planta corresponde ao comprimento do ramo principal medido a partir do nível do solo. Foram também anotados os estádios de desenvolvimento $\mathrm{V}, \mathrm{R}$ e $\mathrm{R}$, que correspondem, respectivamente, a emergência, início de florescimento e maturidade de colheita, descritos por FERNANDEZ et al. (1985).

Os dados foram analisados como um experimento trifatorial ( 2 anos $\mathrm{x} 3$ épocas $\mathrm{x} 8$ cultivares) com as seguintes causas de variação: ano (A); época (B); cultivares (C); interações entre $\mathrm{A}, \mathrm{B}$ e $\mathrm{C}$; bloco dentro de ano x época; e erro médio. Para os testes de hipótese sobre os efeitos do modelo foi usado o erro médio. As médias foram comparadas pelo teste de Duncan em 5\% de probabilidade. Para efeito de análise estatística, os dados de número de legumes/ planta foram transformados para raiz quadrada.

\section{RESULTADOS E DISCUSSÃO}

As condições climáticas ocorridas no período de condução do experimento podem ser consideradas normais para a região, ou seja, chuvas bem distribuídas e temperaturas amenas.

A análise estatística acusou interação significativa entre anos de cultivo e épocas de semeadura para todas as características avaliadas (Tabela 1). No entanto, essa interação foi considerada apenas em termos da média das cultivares, pois não tem importância conhecer o desempenho de uma determinada cultivar em um ano, devido este evento não ser repetido. As diferenças significativas ocorridas entre os anos de cultivo aumentam a representatividade dos resultados obtidos.

Em relação à duração dos subperíodos de desenvolvimento, observou-se que no ano 2 foram necessários um maior número de dias para completar o ciclo,
Tabela 1 - Comportamaxto mádio de cito cultivares da fajja am trís ápocas de semeadura em dis aros de cultivo para a duraša dos sub-perídre, altura de planta, múmero de legures/planta e de gräoslegume, peso de 1000 grícos a maxdirtex to de grấc6. Lages, SC, 1996.

\begin{tabular}{|c|c|c|c|}
\hline \multirow[t]{2}{*}{ Epocas de Serreadura } & מ. & $4 x D_{2}$ & Thads \\
\hline & \multicolumn{3}{|c|}{ Dix da emergincia a inucio de florscimento } \\
\hline $\begin{array}{l}\text { Novernbro } \\
\text { Dezembro } \\
\text { Janaiss }\end{array}$ & $\begin{array}{l}48,0 \\
430 \\
37,0\end{array}$ & $\begin{array}{l}61,0 \\
520 \\
55,0\end{array}$ & $\begin{array}{l}54,5 \\
47,5 \\
46,0\end{array}$ \\
\hline Media & 427 & 560 & 494 \\
\hline
\end{tabular}

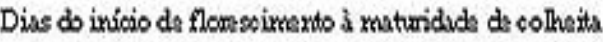

\begin{tabular}{|c|c|c|c|}
\hline $\begin{array}{l}\text { Novernbro } \\
\text { Desestro } \\
\text { Janeiro }\end{array}$ & $\begin{array}{l}43,0 \\
40,0 \\
35,0\end{array}$ & $\begin{array}{l}54,0 \\
49,0 \\
51,0 \\
\end{array}$ & $\begin{array}{l}48,5 \\
44,5 \\
43,0 \\
\end{array}$ \\
\hline \multirow[t]{2}{*}{ Média } & 39,3 & 51,3 & 45,3 \\
\hline & \multicolumn{3}{|c|}{ Altura de planta (cm) } \\
\hline $\begin{array}{l}\text { Novambro } \\
\text { Dezernbro } \\
\text { Janeiro }\end{array}$ & $\begin{array}{l}30,7 \mathrm{Ba}^{2} \\
37,3 \mathrm{~B} \mathrm{~b} \\
28,6 \mathrm{~A}\end{array}$ & $\begin{array}{l}721 \mathrm{Aa} \\
465 \mathrm{~A} \text { b } \\
289 \mathrm{~A} \mathrm{c}\end{array}$ & $\begin{array}{l}55,9 \mathrm{a} \\
41,9 \mathrm{~b} \\
28,8 \mathrm{c}\end{array}$ \\
\hline \multirow[t]{2}{*}{$\begin{array}{l}\text { Mïdis } \\
\text { CW\% }\end{array}$} & $\begin{array}{l}35,2 \\
10,2 \\
\end{array}$ & $\begin{array}{l}49,2 \\
11,7\end{array}$ & $\begin{array}{l}42,2 \\
11,4\end{array}$ \\
\hline & \multicolumn{3}{|c|}{ Nitunem de leguxnesiplanta } \\
\hline $\begin{array}{l}\text { Novernbro } \\
\text { Dentubro } \\
\text { Jameiro }\end{array}$ & $\begin{array}{l}13,2 \mathrm{Bb} \\
14,6 \mathrm{Aa} \\
95 \mathrm{~A} \mathrm{C}\end{array}$ & $\begin{array}{r}19,7 \mathrm{~A} a \\
14,5 \mathrm{~A} \mathrm{~b} \\
8,0 \mathrm{~B} \mathrm{c}\end{array}$ & $\begin{array}{l}16,5 \mathrm{a} \\
14,6 \mathrm{~b} \\
8,8 \mathrm{c}\end{array}$ \\
\hline \multirow[t]{2}{*}{$\begin{array}{l}\text { Media } \\
\text { CV\% }\end{array}$} & $\begin{array}{c}124 \\
811 \\
\end{array}$ & $\begin{array}{c}14,4 \\
0,4 \\
\end{array}$ & $\begin{array}{r}133 \\
8,8 \\
\end{array}$ \\
\hline & \multicolumn{3}{|c|}{ Nímero de grãosilegure } \\
\hline $\begin{array}{l}\text { Novembro } \\
\text { Dezernbro } \\
\text { Janeino }\end{array}$ & $\begin{array}{l}4,2 \mathrm{~B} \mathrm{~b} \\
4,4 \mathrm{~A}_{\mathrm{ab}} \\
4,5 \mathrm{Aa}\end{array}$ & $\begin{array}{l}4,7 \mathrm{Aa} \\
3,9 \mathrm{~B} \mathrm{c} \\
4,2 \mathrm{~B} \mathrm{~b}\end{array}$ & $\begin{array}{l}4,5 \mathrm{a} \\
4,2 \mathrm{~b} \\
4,4 \mathrm{ab}\end{array}$ \\
\hline \multirow[t]{2}{*}{$\mathrm{CV} \%$} & $\begin{array}{r}4,4 \\
131 \\
\end{array}$ & $\begin{array}{r}4,3 \\
11,7 \\
\end{array}$ & $\begin{array}{r}4,4 \\
124 \\
\end{array}$ \\
\hline & \multicolumn{3}{|c|}{ Peso de 1000 gु̆ } \\
\hline $\begin{array}{l}\text { Novambro } \\
\text { Dezembro } \\
\text { Janeim }\end{array}$ & $\begin{array}{l}20,0 \mathrm{~A} \text { a } \\
10,3 \mathrm{~A} \text { a } \\
16,6 \mathrm{~A} \text { b }\end{array}$ & $\begin{array}{l}10,1 \mathrm{Ba} \\
16,4 \mathrm{~B} \text { b } \\
16,1 \mathrm{~A} \mathrm{~b}\end{array}$ & $\begin{array}{l}19,6 \mathrm{a} \\
179 \mathrm{~b} \\
164 \mathrm{c}\end{array}$ \\
\hline \multirow[t]{2}{*}{$\begin{array}{l}\text { Mëdia } \\
\text { CW\% }\end{array}$} & $\begin{array}{l}78,6 \\
7,8 \\
\end{array}$ & $\begin{array}{l}17,2 \\
11,1 \\
\end{array}$ & $\begin{array}{l}180 \\
94 \\
\end{array}$ \\
\hline & \multicolumn{3}{|c|}{ Rendimento de gros (0a/ha) } \\
\hline $\begin{array}{l}\text { Novernbro } \\
\text { Denarboro } \\
\text { Jameirs }\end{array}$ & $\begin{array}{l}2001 \mathrm{Ba}_{a} \\
1875 \mathrm{~A} \text { b } \\
1041 \mathrm{~A} \mathrm{c}\end{array}$ & $\begin{array}{l}222 \mathrm{Aa} \\
1310 \mathrm{~B} \mathrm{~b} \\
785 \mathrm{~B} \text { c }\end{array}$ & $\begin{array}{l}2111 \mathrm{a} \\
193 \mathrm{~b} \\
913 \mathrm{c}\end{array}$ \\
\hline $\begin{array}{l}\text { Media } \\
\text { CV\% }\end{array}$ & $\begin{array}{l}1698 \\
15,39\end{array}$ & $\begin{array}{c}1430 \\
163\end{array}$ & $\begin{array}{l}1590 \\
161\end{array}$ \\
\hline
\end{tabular}

FMädias rão segridas pela meana latra mírscula na linha \& mixúsoula na coluna diferem pelo teste de Duxcanem $\$$ de probabilidade. 
sendo que o atraso da semeadura ocasionou a redução dos sub-períodos de desenvolvimento. Esta redução está associada ao aumento da temperatura e conseqüentemente ao acúmulo térmico, que acelera o desenvolvimento das plantas (FERNANDEZ et al., 1985; THOMÉ, 1985). O aumento dos sub-períodos de desenvolvimento proporcionou um incremento significativo na altura de planta no ano 2, com exceção da semeadura feita em meados de janeiro. Por outro lado, o atraso da semeadura levou a redução significativa da altura de planta nos dois anos de cultivo, resposta já esperada em função da maior disponibilidade térmica. Resultados similares foram obtidos por THOMÉ (1985), que justificou a diminuição da altura de planta devido as restrições no crescimento, explicáveis pela análise da taxa de crescimento da cultura e pelo encurtamento do ciclo.

Para os componentes do rendimento e principalmente o rendimento de grãos, o atraso da semeadura levou à redução significativa destes em ambos os anos de cultivo. No entanto, esta redução do rendimento de grãos esteve mais associado ao número de legumes/planta e ao peso de 1000 grãos no ano $1 \mathrm{e}$ a todos os componentes de rendimento no ano 2 . Também, a redução do rendimento devido ao atraso da semeadura foi menor no ano 1 do que no ano 2, mostrando que as condições ambientais ocorridas naquele ano foram mais favoráveis durante todo o ciclo da cultura, quando a semeadura foi efetuada em meados de dezembro e de janeiro.

A semeadura tardia afetou de forma diferenciada o comportamento das cultivares em termos de altura de planta (Tabela 2). Isso pode ser verificado, como por exemplo, com as cultivares Macanudo e Barriga Verde, que apresentaram diferenças significativas na altura de planta nas semeaduras de novembro e de dezembro, o que não ocorreu na semeadura de janeiro. Em geral, o atraso da semeadura reduziu significativamente a altura de planta com exceção somente para a cultivar Macanudo entre as semeaduras de dezembro e de janeiro. $\mathrm{Na}$ média das cultivares, na semeadura de dezembro as plantas cresceram $74,9 \%$ e as de janeiro apenas $51,3 \%$, em relação a semeadura que foi efetuada em novembro.

Estes resultados mostram que a prática do atraso da semeadura deveria ser acompanhado do aumento da densidade e adequação do arranjo de plantas. O aumento da densidade, bem como uma melhor distribuição das plantas, intensifica a competição entre as plantas, favorecendo a rápida cobertura do solo, com incremento da altura de planta e, como conseqüência, o melhor aproveitamento da radiação solar (THOMÉ, 1985; KRANZ, 1989). Nesta condição, o carbono utilizado para o crescimento do caule, em resposta a maior competição, não é retirado do crescimento de outros órgãos, mas sim resultante da maior fotossíntese líquida que a planta em comunidade passa a ter (BALLARÉ et al., 1991).

$O$ atraso da semeadura também proporcionou diferentes respostas das cultivares em termos de número de legumes/planta (Tabela 3). O atraso da semeadura afetou significativamente o número de legumes/planta somente na semeadura de janeiro, com exceção da cultivar FT-Tarumã que apresentou menor número de legumes/planta já na semeadura de dezembro. Na média das cultivares, a redução do número de legumes/planta foi da ordem de $11,6 \%$ para a semeadura de dezembro e de $46,3 \%$ para a de janeiro, em relação a semeadura efetuada em novembro. Não foi verificado variação para esta característica entre cultivares na semeadura de dezembro, já em novembro e janeiro foram verificadas diferenças significativas, sendo que as cultivares Macanudo e Barriga Verde foram as que apresentaram maior número de legumes/planta, considerando as três épocas de semeadura. Todas as cultivares apresentaram o mesmo comportamento nas diferentes épocas de semeadura 
Tabela 3-Médiade dois aros de cultivo do rúmero de leguresiplanta de cito

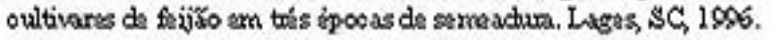

\begin{tabular}{|c|c|c|c|c|}
\hline \multirow[t]{2}{*}{ Cultivares } & \multicolumn{3}{|c|}{ Épocas de Serneadura } & \multirow[t]{2}{*}{ Média } \\
\hline & Noverabro & Dezembio & Jareiro & \\
\hline $\begin{array}{l}\text { Macarodo } \\
\text { Barriga Verle } \\
\text { FT-Tanumí } \\
\text { Rio Tibaji } \\
\text { Carioca } 80 \\
\text { FMPASC } 201 \\
\text { FT-120 } \\
\text { Carioca }\end{array}$ & $\begin{array}{l}16,3 \mathrm{~A} \mathrm{~b}^{*} \\
16,9 \mathrm{~A} \mathrm{ab} \\
20,0 \mathrm{Aa} \\
16,5 \mathrm{~A} \mathrm{ab} \\
16,1 \mathrm{~A} \mathrm{~b} \\
15,4 \mathrm{~A} \mathrm{~b} \\
15,1 \mathrm{~A} \mathrm{~b} \\
14,8 \mathrm{~A} \mathrm{~b}\end{array}$ & $\begin{array}{l}15,1 \mathrm{Aa} \\
14,5 \mathrm{Aa} \\
14,2 \mathrm{Ba} \\
14,4 \mathrm{Ba} \\
14,6 \mathrm{~A} \mathrm{a} \\
14,8 \mathrm{~A} \mathrm{a} \\
14,2 \mathrm{~A} \mathrm{a} \\
14,4 \mathrm{~A} a\end{array}$ & $\begin{array}{l}11,4 \mathrm{~B} \mathrm{a} \\
9,5 \mathrm{~B} \mathrm{ab} \\
7,5 \mathrm{C} \mathrm{bc} \\
9,2 \mathrm{~B} \text { b } \\
8,7 \mathrm{~B} \quad \mathrm{~b} \\
8,8 \mathrm{~B} \text { b } \\
8,6 \mathrm{~B} \text { bo } \\
6,7 \mathrm{~B} \quad \mathrm{c}\end{array}$ & $\begin{array}{l}14,2 \mathrm{a} \\
13,4 \mathrm{ab} \\
13,4 \mathrm{ab} \\
13,2 \mathrm{ab} \\
12,9 \mathrm{abc} \\
12,8 \mathrm{abc} \\
12,4 \mathrm{~b} \\
11,6 \mathrm{c}\end{array}$ \\
\hline $\begin{array}{l}\text { Modein } \\
\text { CV\% }\end{array}$ & $\begin{array}{l}16,4,4 \\
9,8\end{array}$ & $\begin{array}{l}14,5 \mathrm{~B} \\
6,6\end{array}$ & $\begin{array}{r}8,8 \mathrm{C} \\
10,9\end{array}$ & $\begin{array}{c}13,0 \\
8,8\end{array}$ \\
\hline
\end{tabular}

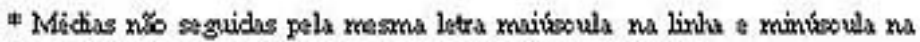
columa diferem pelo teste de Durcan era $5 \%$ de probabilidade.

quando avaliados o número de grãos/legume e o peso de 1000 grãos (Tabela 4). O número de grãos/legume apresentou variação da ordem de $17,0 \%$ entre a cultivar com maior e menor valor, respectivamente para as cultivares Macanudo e Barriga Verde. O mesmo ocorreu para o peso de 1000 grãos, onde identificou-se uma variação de $26,5 \%$ entre a cultivar com grãos mais pesados e mais leves, respectivamente para as cultivares Macanudo e Rio Tibaji. As cultivares Macanudo e Carioca 80 que apresentaram, em termos absolutos, o maior peso de 1000 grãos, também produziram o maior número de grãos/legume. Este não é um comportamento comum pois o menor número de grãos/legume é compensado pelo maior peso de 1000 grãos (BROTHERS \& KELLY, 1993), indicando que estas cultivares apresentam boa eficiência fotossintética em semeadura tardia.

$O$ atraso da semeadura afetou significativamente o rendimento de grãos de todas as cultivares avaliadas (Tabela 5), porém o nível de redução foi variável entre as cultivares. A redução do rendimento de grãos, na média das cultivares, foi da ordem de $24,6 \%$ para a semeadura de dezembro e de $56,7 \%$ para a semeadura de janeiro, em relação a época recomendada. A cultivar menos afetada pelo atraso da semeadura foi a Macanudo que, na média dos dois anos, apresentou o maior rendimento em todas as épocas, não diferindo estatisticamente apenas das cultivares Carioca 80 e Barriga Verde na semeadura de novembro e da Carioca 80 na semeadura de dezembro. A manutenção da alta produtividade da cultivar Macanudo, comparada com as demais, se deve ao fato de que esta cultivar apresentou, em termos absolutos, o maior número de legumes/planta na semeaduras de dezembro e de janeiro (Tabela 3), o maior número de grãos/legume e peso de 1000 grãos (Tabela 4), o que compensou o rendimento de grãos. Estes resultados indicam que algumas cultivares apresentam maior potencial de uso em semeadura tardia ou, pelo menos, que nem todas as cultivares devam ser recomendadas com esta prática cultural.

Sabendo que a semeadura tardia no planalto catarinense afeta significativamente o rendimento de grãos, principalmente na semeadura de janeiro, mas que ao mesmo tempo esta é uma prática que vem sendo utilizada na região, é importante analisar o comportamento específico das diferentes cultivares recomendadas. Neste sentido, é importante destacar a capacidade produtiva apresentada pelas cultivares Macanudo, Carioca 80 e Barriga Verde. Especificamente para a semeadura de dezembro, se destacaram as cultivares Macanudo e Carioca 80 e para a semeadura de janeiro somente a cultivar Macanudo.

Tabela 4 - Mádia de dois axos de cultivo do rúntrem de grás:legrane e peso de 1000 grãos (g) de oit cultivares de feijüo em träs ápooas de serneadura. Lages, \$C, 1996.

\begin{tabular}{|c|c|c|}
\hline Cultivares & Núrem de gyäoslegume & Peso de 1000 grắos \\
\hline $\begin{array}{l}\text { Macurato } \\
\text { Cariosa } 80 \\
\text { EMPasC } 201 \\
\text { Carioca } \\
\text { Rio Tibaji } \\
\text { FT-1 20 } \\
\text { FT-Tanans } \\
\text { Bariga Vemle }\end{array}$ & $\begin{array}{l}4,7 \mathrm{x}^{ \pm} \\
4,6 \mathrm{a} \\
4,5 \mathrm{a} \\
4,4 \mathrm{ab} \\
4,2 \mathrm{bo} \\
4,1 \mathrm{c} \\
4,0 \circ \\
3,9 \mathrm{c}\end{array}$ & $\begin{array}{l}200,02 \\
198,0 \mathrm{a} \\
178,0 \mathrm{od} \\
184,0 \mathrm{be} \\
147,0 \text { f } \\
165,0 \text { e } \\
170,0 \text { de } \\
191,0 \mathrm{ab}\end{array}$ \\
\hline $\begin{array}{l}\text { Módia } \\
\text { CW\% }\end{array}$ & $\begin{array}{c}4,3 \\
12,4\end{array}$ & $\begin{array}{r}179,0 \\
9,4\end{array}$ \\
\hline
\end{tabular}

*Medias río seguides pela messna leta reziriscula na linha e minúscula ra coluna diferem pelo teste de Duncan em $5 \%$ de probabilidade. 
Tabela S - Mádia de dois amos de cullivo do rendixnerto de gixios (Jutha) de oito cultivares de féjja em trís ipoeas de semeadra. Lages SC, 1996.

\begin{tabular}{|c|c|c|c|c|}
\hline \multirow[t]{2}{*}{ Cultivanes } & \multicolumn{3}{|c|}{ Epocas de Sernaaduma } & \multirow[t]{2}{*}{ Meda } \\
\hline & Novembro & Dezerribo & Janeiro & \\
\hline $\begin{array}{l}\text { Macarando } \\
\text { Carioes } 80 \\
\text { Bariza Verds } \\
\text { EMMPASC } 201 \\
\text { FT-1 10 } \\
\text { Rio Tibaji } \\
\text { FT-Tanera } \\
\text { Carioca }\end{array}$ & $\begin{array}{l}2449,9 \mathrm{~A} \mathrm{a}^{*} \\
2460,1 \mathrm{Aa} \\
2447, \mathrm{AA} \mathrm{a} \\
1924,7 \mathrm{~A} \mathrm{~b} \\
1924,2 \mathrm{~A} \mathrm{~b} \\
1984,7 \mathrm{~A} \mathrm{~b} \\
1856,3 \mathrm{~A} \mathrm{~b} \\
1839,1 \mathrm{~A} \mathrm{~b}\end{array}$ & $\begin{array}{l}1979,5 \mathrm{~B} \mathrm{a} \\
1784,2 \mathrm{~B} \text { ab } \\
16169,9 \mathrm{~B} \text { bo } \\
1694,5 \mathrm{~B} \text { bc } \\
1639,1 \mathrm{~B} \text { bo } \\
1454,2 \mathrm{~B} \text { od } \\
1309,7 \mathrm{~B} \text { d } \\
1320,6 \mathrm{~B} \text { d }\end{array}$ & $\begin{array}{l}1364,0 \mathrm{Ca} \\
915,6 \mathrm{Cbod} \\
1016,4 \mathrm{C} \\
1068,8 \mathrm{Cb} \\
818,0 \mathrm{C} \text { cde } \\
731,3 \mathrm{C} \text { d } \\
755,3 \mathrm{C} \text { d } \\
634,9 \mathrm{C} \text { \& }\end{array}$ & $\begin{array}{l}1931,1 \mathrm{a} \\
1720,0 \mathrm{~b} \\
193,6 \mathrm{~b} \\
1542,6 \mathrm{c} \\
1450,4 \mathrm{~cd} \\
1300,0 \mathrm{~d} \\
1307,1 \text { : } \\
1264,9 \text { ? }\end{array}$ \\
\hline $\begin{array}{l}\text { MBdia } \\
\text { CV\% }\end{array}$ & $\begin{array}{c}16,4 \mathrm{M} \\
9,8\end{array}$ & $\begin{array}{c}14,5 \mathrm{~B} \\
6,6\end{array}$ & $\begin{array}{c}8,8 \mathrm{C} \\
109\end{array}$ & $\begin{array}{r}13,0 \\
8,8\end{array}$ \\
\hline
\end{tabular}

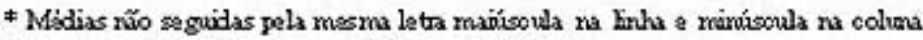
diferem pelo teste de Durveanem $\$ \%$ de probabilidide.

Além da importância da escolha das cultivares, também é importante considerar a época de semeadura. Para esta região, de temperaturas amenas, o prolongamento da época de semeadura para o meses de dezembro e de janeiro são aceitáveis pelos tetos produtivos alcançados neste experimento. Por outro lado, quando a semeadura foi efetuada em meados de janeiro, ocorreu uma redução bastante acentuada do rendimento de grãos, devido as limitações das condições climáticas de final do ciclo, onde se verifica uma queda acentuada na disponibilidade térmica. Assim sendo, a recomendação prolongada da época de semeadura de feijão para o planalto catarinense, feita a partir do ano agrícola de 1994/95 que se estende de 15 de novembro a 15 de janeiro (HEMP et al., 1994) deve ser mantida, porém os resultados deste experimento, que subsidiaram as novas recomendações, dão suporte ao fato de que, durante este período, a semeadura deva ser realizada o mais rápido possível. Durante o período da recomendação prolongada, na média de oito cultivares e dois anos de cultivo, cada dia de atraso da semeadura correspondeu a uma redução de $0,95 \%$ no rendimento de grãos, o que eqüivale, nas condições do experimento, a uma redução diária da produtividade na ordem de $20 \mathrm{~kg} /$ ha de grãos.

A escolha da época de semeadura é importante pois determina as condições climáticas que estarão disponíveis durante todo o ciclo da cultura (SINCLAIR, 1994). A temperatura média do ar afeta o comprimento dos sub-períodos de desenvolvimento das plantas, principalmente o sub-período emergência-início de florescimento (VIEIRA et al., 1990). O menor período entre a emergência e o início de florescimento proporcionou um tempo menor para o crescimento das plantas, resultando na menor cobertura do solo e menor capacidade fotossintética. A menor capacidade fotossintética se manifestou sobre todos os componentes do rendimento $\mathrm{e}$, conseqüentemente, sobre o rendimento de grãos. $\mathrm{O}$ efeito de época de semeadura foi mais marcante sobre o número de legumes/planta, pois o atraso na semeadura limitou a capacidade das plantas para o enchimento de um maior número de legumes.

A menor disponibilidade térmica aumenta demasiadamente o sub-período início de floraçãomaturidade de colheita. O aumento deste sub-período é sempre um objetivo, já que as plantas permanecem por mais tempo realizando fotossíntese e translocando para os grãos (JONES et al., 1996). Porém, neste caso, os valores de temperaturas mínimas são muito baixos, o que podem afetar o florescimento e, conseqüentemente, o número de grãos/legume. Em face dos resultados de rendimento de grãos e desta análise, os produtores de feijão do planalto catarinense devem evitar a semeadura em janeiro, já que as limitações climáticas são muito acentuadas. Por outro lado, os trabalhos de pesquisa deveriam ser continuados buscando formas para equacionar este problema. A adequação da densidade e do arranjo de plantas, bem como a determinação dos níveis de resposta a adubação, são fundamentais para a maximização do rendimento de grãos em cultivos tardios de feijão no planalto catarinense.

\section{CONCLUSÕES}

$\mathrm{O}$ atraso da semeadura de feijão no planalto catarinense reduz significativamente o rendimento de grãos; a indicação desta prática deve ser acompanhada da recomendação de cultivares específicas e de um manejo adequado; e considerando as recomendações de manejo disponíveis para a cultura do feijão, a cultivar BR/IPAGRO 1-Macanudo é a de melhor desempenho em semeadura tardia no planalto catarinense. 


\section{REFERÊNCIAS BIBLIOGRÁFICAS}

ALMEIDA, M.L. de, SANGOI, L. Manejo de cultivares de feijão de diferentes habitos de crescimento no planalto catarinense. I Rendimento de grãos. Ciência Rural, Santa Maria, v. 24, n. 3, p. 513-517. 1994.

BALDISSERA, I.T., SCHERER, E.E. Correção da acidez do solo e adubação da cultura do feijão. In: EPAGRI. A cultura do feijão em Santa Catarina. EPAGRI, Florianópolis, 1992. p. 115-136. 285 p.

BALLARÉ, C.L., SCOPEL, A.L., SÁNCHEZ, R.A. On the oportunity cost of the photosyntate invest in stem elongation reactions medited by phytochrome. Oecologia. n. 86, p. $561-$ 567. 1991.

BROTHERS, M.E., KELLY, J.D. Interrelationship of plant architecture and yield components in the pinto bean ideotype. Crop Science, Madison, v. 33, p. 1234-1238. 1993.

FERNANDEZ, F., GEPTS, P., LOPEZ, M. Etapas de desarollo em la planta de frijol. In: LOPES, M., FERNANDEZ, F., SCHOONHOVEN, A. Frijol, investigación y produción. Cali, Colômbia, CIAT, 1985. p. 61-78.

HEMP, S., MASSIGNAM, A.M., GANDIM, C.L. et al. Feijão. In: EPAGRI. Recomendações de cultivares para o estado de Santa Catarina 1993/1994. Boletin Técnico n. 63. p. 52-58. 1993. $118 \mathrm{p}$

HEMP, S., MASSIGNAM, A.M., GANDIM, C.L. et al. Feijão. In: EPAGRI. Recomendações de cultivares para o estado de Santa Catarina 1994/1995. Boletin Técnico n. 67. p. 55-61. 1994. $136 \mathrm{p}$.

INSTITUTO CEPA. Informe conjuntural. Intituto CEPA/SC. Florianópolis, ano XVI, n. 603. 1996.

JONES, R.J., SCHREIBER, B.M.N., ROESSLER, J.A. Kernel sink capacity in maize: genotipic and maternal regulation. Crop Science, Madison, v. 36, p. 301-306. 1996.
KRANZ, W.M. População de plantas. In: IAPAR. O feijão no Paraná. IAPAR, Londrina, 1989. p. 115-126. 303 p.

MILANEZ, J.A. Pragas do feijoeiro. In: EPAGRI. A cultura do feijão em Santa Catarina. EPAGRI, Florianópolis, 1992. p. 179-193. 285 p.

MIRANDA, G.V., VIEIRA, C., CRUZ, C.D., et al. Adaptabilidade e estabilidade de comportamento de cultivares de feijão em quatro municípios da zona da mata de Minas Gerais. Revista Ceres, Viçosa, v. 41, n. 232, pl 591-609. 1993.

ORTEGA, N.A.U., VIVES, L., ZUNIGA, A.C. Exigencias climáticas del Phaseolus vulgaris L. durante agosto-diciembre. Alajuela: Universidad de Costa Rica. 1974. 46 p. (Boletin Técnico, 2).

SINCLAIR, T.R. Limits to crop yield. In: BOOTE, K.J. et al. Physiology and determination of crop yield. Asa, Madison, p. 509-532, 1994. 601 p.

THOMÉ, V.M.R. Crescimento, desenvolvimento e rendimento de grãos de uma cultivar de feijoeiro de hábito de crescimento arbustivo determinado, em função da época de semeadura, espaçamento entre linhas e densidade de plantas. Porto Alegre, RS, 139 p. Tese (Mestrado em Agronomia) - Curso de Pós-graduação em Agronomia. Universidade Federal do Rio Grande do Sul, 1985.

VIEIRA, H.J., BERGAMASCHI, H., COUTINHO, A.R., et al. Disponibilidade hídrica do solo e eficiência do feijoeiro em utilizar água e radiação solar. Pesquisa Agropecuária Brasileira, Brasília, v. 25, n. 10, p. 1249-1445. 1990.

VIEIRA, C., FARIA VIEIRA, R. Épocas de plantio do feijão e proposta de nomenclatura para designá-las. Revista Ceres, Viçosa, v. 42, n. 244, p. 685-688. 1995.

WILDNER, L.P. Manejo do solo para a cultura do feijão: principais características e recomendações técnicas. In: EPAGRI. A cultura do feijão em Santa Catarina. EPAGRI, Florianópolis, 1992. p. 83-114. 285 p. 